
3

\title{
Tracing ancient evolutionary divergence in parasites
}

RICHARD C. TINSLEY ${ }^{1 *}$ and MATTHEW C. TINSLEY²

${ }^{1}$ School of Biological Sciences, University of Bristol, Bristol BS8 1TQ

${ }^{2}$ School of Biological and Environmental Sciences, University of Stirling, Stirling, FK9 4LA 4

.

(

\section{Running title: Evolution of Polystomoides}

*Corresponding author: School of Biological Sciences, Life Sciences Building, University of Bristol, Bristol BS8 1TQ, U.K. E-mail: r.c.tinsley@bristol.ac.uk 
For parasitic platyhelminths that generally lack a fossil record, there is little information on the pathways of morphological change during evolution. Polystomatid monogeneans are notable for their evolutionary diversification, having originated from ancestors on fish and radiated in parallel with tetrapod vertebrates over more than 425 million years. This study focuses on the genus Polystomoides that occurs almost worldwide on freshwater chelonian reptiles. Morphometric data show a major divergence in structural adaptations for attachment; this correlates with a dichotomy in micro-environmental conditions in habitats within the hosts. Species infecting the urinary tract have attachment organs with large hamuli and small suckers; species in the oro-nasal tract differ fundamentally, having small hamuli and large suckers. Zoogeographical and molecular evidence supports ancient separation of these site-specific clades: a new genus is proposed - Uropolystomoides containing urinary tract species distinct from Polystomoides sensu stricto in oro-nasal sites. Aside from differences in attachment adaptations, body plans have probably changed little over perhaps 150 million years. This case contrasts markedly with polystomatids in other vertebrate groups where major morphological changes have evolved over much shorter timescales; the chelonian parasites show highly stable morphology across their global distribution over a long period of evolution, exemplifying 'living fossils'.

Key words: Monogenea, Polystomatidae, Polystomoides, Uropolystomoides, living fossils, site-specific attachment adaptations

(1)


63

64

65

66

67

68

69

70

71

72

73

74

75

76

77

76

Key findings / bullet points:

Polystomatid monogeneans have an ancient phylogeny, originating over 425 Million years ago

DNA, morphology and continental drift show Polystomoides is unchanged since the Jurassic

Morphometric analysis reveals a split into lineages separated by site-specific attachment

The age of these events predates evolution of mammals and of all mammalian parasites

Polystomoides spp typify 'living fossils' for which this account creates a new genus 


\section{INTRODUCTION}

Reconstruction of evolution in animal groups with a fossil record may benefit from a sequence of intermediate forms preserved in successive geological strata, illustrating how present-day representatives could have changed over time. With few exceptions (e.g. De Baets and Littlewood, 2015; Leung, 2016), platyhelminth parasites have no fossil record: interpretation of evolutionary change must be deduced from the current tips of branches of phylogenetic trees, without indication of morphology at successive stages of diversification. Calibrated molecular phylogenies provide a guide to the timescales of parasite lineages but there is still little knowledge of the body forms of ancestors.

One group of platyhelminth monogeneans, the Polystomatidae, provides a comprehensively-studied system in which parasite phylogeny can be traced over an exceptionally long period of evolutionary time, from an estimated origin around 425 million years ago (Mya) (Verneau et al. 2002). This family has diversified in parallel with vertebrate evolution with lineages infecting a lungfish, all groups of amphibians (caecilians, anurans and urodeles), one group of reptiles (chelonians), and one mammal - the Hippopotamus. The problems of interpreting pathways of evolutionary change are illustrated by reference to the single species exploiting a mammal. Oculotrema hippopotami has a body plan that is highly divergent from all other polystomatids and its suite of unusual features suggests an ancient origin (Tinsley, 2013). Recent molecular analysis has dated the origin of this lineage to around 152 Mya (Héritier et al. 2015), long before the appearance of possible mammalian hosts. It must be assumed that the ancestors of Oculotrema diverged whilst infecting another host group, perhaps now extinct: studies of larval characters (Tinsley, 2013) and molecular phylogeny (Héritier et al. 2015) suggest this was probably a polystomatid infecting chelonians. But there are no clues to the evolutionary steps leading to the unique combination of characters distinguishing this parasite. In other words, we have no idea what this exceptional parasite looked like in the Jurassic. Whilst this single 'Oculotrema clade' is notable for its long timescale and extent of divergence, a similar lack of knowledge of evolutionary steps is common amongst platyhelminths. The present study examines another of the evolutionary branches within the Polystomatidae, one that infects 
chelonian reptiles, to investigate evidence of deep-rooted morphological divergence in this parasite clade.

Transmission of polystomatid monogeneans employs an aquatic infective stage, the oncomiracidium, and the diverse groups of vertebrate hosts are linked by their occurrence in water at the time of invasion. Life cycles typically achieve close synchrony of parasite transmission with host ecology, reproduction and behaviour (Tinsley, 1993, 2004). Amongst representatives infecting anuran amphibians (the largest group in the Polystomatidae), variations in body organisation may be interpreted as independent solutions to enable mass storage of eggs for rapid release when hosts are vulnerable to invasion (Tinsley, 1990). The genera are distinguished by different combinations of states of reproductive, digestive and attachment organs, and these variations make evolutionary diversity easy to recognise (Tinsley, 1983). At the time of the major review by Price (1939), 3 genera of polystomatids infecting anurans were distinguished; now there are 16. By contrast, the basic body plan of polystomatids infecting chelonians (the second largest group) exhibits little variation: most structures, except for the attachment organs, are closely comparable across the taxa. This uniformity is reflected in taxonomic stasis at the level of genus despite increasing numbers of species: 75 years ago, 3 genera were recognised (Price, 1939); the current total is still 3. These genera are distinguished simply by the number of large hooks or hamuli carried on the posterior haptor: species of Polystomoides have 2 pairs of hamuli, Polystomoidella spp. have 1 pair and Neopolystoma spp. have none (Price, 1939).

This study focuses on the genus Polystomoides whose species infect either the urinary tract or the oral cavity and associated passages of chelonians. The distinctiveness of Polystomoides was first recognised by Ward (1917) and, apart from refinement of diagnostic features, the genus has remained constant ever since. Rohde (1965) identified a dichotomy between species of Polystomoides infecting the alternative sites at anterior or posterior of the host's body and used this in a taxonomic key. Tinsley (1971, unpublished Ph.D. thesis, University of Leeds) was the first to consider evolutionary divergence within Polystomoides based on functional morphology. In the then-known 17 species, 2 groups were distinguished based on adaptations of their attachment organs; the differences supported 
separation of 2 site-specific lineages as distinct genera. However, this conclusion and the new genus proposed was never formally published. Some subsequent studies, including Knoepffler and Combes (1977), have independently made the same observation of 2 evolutionary lines within Polystomoides. Zoogeographical evidence suggests that these parasites represent an ancient group which radiated among chelonian lineages before the break-up of Pangaea, perhaps 200 Mya (Rohde and Pearson, 1980). Littlewood et al. (1997) examined molecular evidence for the involvement of sympatric or allopatric speciation in the evolution of Polystomoides. Their results showed unequivocally that distinct sitespecific clades occur within the genus. A series of molecular phylogenetic analyses has supported this separation (Verneau et al. 2002; Olsen and Littlewood, 2002; Héritier et al. 2015), but none has considered the significance of the divergence for systematics.

The present account is based primarily on the unpublished study of Tinsley $(1971$, loc. cit.) up-dated to include 31 currently-recognised species. Parasite evolution is considered initially in relation to adaptations to contrasting micro-environmental conditions within the body of the host. Interpretation is reinforced by evidence of biogeography, host phylogeny, parasite larval characteristics and, conclusively, from published molecular analyses. We argue that the evidence justifies creation of a new genus of polystomatid (defined in Appendix 1). Two associated outcomes of this analysis provide rare insight into evolutionary change in parasites. First, it can be deduced that the divergence responsible for this systematic distinction probably occurred in the Jurassic. Second - in contrast to the hippopotamus parasite, Oculotrema, where a similar geological timescale has been accompanied by major morphological changes - the body plan of these 2 lineages of chelonian polystomatids has remained remarkably unchanged over a vast period of evolutionary time.

\section{MATERIALS AND METHODS}

Observations on living specimens were based on field collections in Africa (Uganda, Ghana), Australia and North America, and on hosts imported from N. America and S.E. Asia 
171

172

173

174

175

176

177

178

179

180

181

182

183

184

185

186

187

188

189

190

191

192

193

194

195

196

197

198

199

200

(Thailand). Comparative morphometric data were derived from preserved whole mount specimens, histological sections, and the published descriptions of all the species currently assigned to Polystomoides Ward.

The data set of species descriptions taken from over 100 years of the worldwide literature has several unavoidable limitations. These, and the approach adopted in this study, are addressed in Appendix 2. Following a comprehensive comparison of species characteristics, the measurements employed in the following analyses (recorded in the original descriptions) were: total body length (including the haptor), the lengths of the 2 types of hamuli, and the diameter of the haptoral suckers.

Statistical analysis was carried out in R version 3.2.5. (R Development Core Team, 2016). Morphometric means were compared between species inhabiting bladder and oral cavities using $t$ tests corrected for unequal variance. Allometric relationships between morphometric characters were assessed using linear models: a set of models investigated the association between body length and each of hamulus 1 length, hamulus 2 length and sucker diameter. For each model the explanatory variable 'location' tested whether mean character size differed between species infecting oral and bladder cavities; a "body length by location' interaction tested whether the allometric relationship varied between species infecting the 2 sites.

\section{OBSERVATIONS}

\section{Haptor structure and function}

Species of Polystomoides have 2 distinct sites of infection in their chelonian hosts: either the oral cavity, including the mouth, pharynx, oesophagus and nasal passages, or the urinary tract, including the urinary and accessory bladders, cloaca, kidneys and ducts. (Morrison and Du Preez, 2011 also included 'the cavity of the eye' as an infection site but none of their references specifies this.) Using the present data set of morphometric measurements 
compiled from the literature, the following analysis is based on 20 records of Polystomoides species infecting the anterior sites and 12 infecting posterior sites.

Comparison of maximum metrics recorded for each species (see Appendix 2) shows that the 2 groups of taxa have similar body size ranges: lengths $2.2-7.8 \mathrm{~mm}$ for species infecting oral sites and $2.8-10.1 \mathrm{~mm}$ for those in urinary sites. Mean body length for the 2 groups is not significantly different: oral species $4.89 \mathrm{~mm}$ (SE $\pm 0.37, \mathrm{n}=20$ ); bladder species $5.82 \mathrm{~mm}$ (SE $\pm 0.77, \mathrm{n}=12)\left(\mathrm{t}_{(\mathrm{df}=16.0)}=1.084, P=0.294\right)$.

The major components of the attachment apparatus of the haptor are 6 suckers and 2 pairs of hamuli (referred to here as hamulus 1, the larger, outer pair, and hamulus 2, the smaller, inner pair). These develop and grow continuously following establishment post-infection. In addition, there are 16 marginal hooklets that reach final size before hatching of the oncomiracidium and persist without further growth throughout life.

Species from the alternative sites of infection differ fundamentally in organisation of the haptor. Oral cavity parasites have larger suckers and smaller hamuli compared with urinary tract parasites that have relatively smaller suckers and much larger hamuli (Fig. 1 A-F). In species infecting oral sites, the length of hamulus 1 is, on average, $2.7 \%$ of body length (and never more than 5\%); in urinary tract species, mean hamulus 1 length is nearly $10 \%$ of body length (and never less than 6\%) (Fig. 1D). Variation in hamulus 1 size between the 2 groups of parasites is also non-overlapping when the absolute lengths are considered: hamulus 1 size is $<250 \mu \mathrm{m}$ in all oral species (range $52-200 \mu \mathrm{m}$ ) and $>250 \mu \mathrm{m}$ in all urinary species (range 285-900 $\mu \mathrm{m}$ ) (Fig. 1A). The relative lengths of hamulus 2 show a similar difference between the species groups: mean $1.4 \%$ of body length in oral cavity species, $3.6 \%$ in urinary tract species (Figs. 1B, E). In the case of the suckers, these size differences are reversed in the 2 parasite groups. In species infecting oral sites, the diameter of the suckers is equivalent to nearly $10 \%$ of body length (mean $9.8 \%$ ); this is almost twice the corresponding sucker diameter for species in the urinary tract (mean 5.4\%) (Fig. 1F). All differences in these characters between the 2 parasite groups are highly statistically significant (all $P<0.01$, see Fig. 1). 
Next we assessed the nature of the allometric relationship between body size and attachment organ size for the 2 groups of species. Fig. 2A shows the association between sucker diameter and parasite body length in worms from the oral and urinary tracts. For both groups, increasing worm size is accompanied by a linear increase in sucker size: in oral cavity worms a $1 \mathrm{~mm}$ increase in body length is associated with an increase of $52.52 \mu \mathrm{m}$ (SE \pm 18.01 ) in sucker diameter, in urinary tract worms this figure is $41.28 \mu \mathrm{m}$ (SE \pm 11.30 ); these slopes do not differ significantly between the 2 groups (location by body length interaction: $\left.F_{(1,28)}=0.39, P=0.5377\right)$. Therefore, the allometric scaling relationship between body size and sucker diameter does not differ between parasites inhabiting the 2 host sites. Nevertheless, controlling for body size variation, sucker diameters are on average $178 \mu \mathrm{m}$ (SE \pm 35.04$)$ larger in species infecting the oral cavity than in urinary tract species $\left(F_{(1,29)}=\right.$ 27.06, $P<0.0001)$.

In contrast to the suckers, the allometric scaling relationships for the hamuli are very different in the 2 parasite groups. The sizes of hamulus 1 and hamulus 2 both increase strongly with increasing body size for species infecting the urinary tract (Figs. 2B, C: $F_{(1,10)}=$ 13.93, $P=0.0039$ and $F_{(1,10)}=8.528, P=0.0153$ respectively). Whereas, for species infecting oral sites hamulus sizes increase only marginally with increasing body size, an increase that is not significant for hamulus $1\left(F_{(1,18)}=1.32, P=0.264\right)$, but is significant for hamulus $2\left(F_{(1,18)}\right.$ $=6.78, P=0.018$ ). Strong 'location by body size' interaction terms in the analyses for both hamuli demonstrate that as body size increases hamulus size increases at a significantly lower rate in oral cavity worms than in urinary tract worms (Fig. 2B: hamulus 1, $F_{(1,28)}=$ 10.27, $P=0.0034$; Fig. 2C: hamulus $\left.2, \mathrm{~F}_{(1,28)}=4.64, P=0.0399\right)$.

The dichotomy in morphometrics of the attachment structures is shown most clearly in cases where a single chelonian host species is infected by Polystomoides species in both sites. Across the global range of the host-parasite associations, there are 3 known examples (Fig. 3). Ocadia sinensis (in Taiwan) harbours $P$. microrchis in the oral cavity and $P$. ocadiae in the urinary bladder (Fukui and Ogata, 1936, 1939); Cyclemys amboinensis (Malaysia) harbours P. asiaticus (pharynx) and P. malayi (urinary bladder) (Rohde 1963, 1965); Siebenrockiella crassicollis (Malaysia) harbours P. renschi (pharynx) and P. siebenrockiellae (urinary bladder) (Rohde, 1965). Using the maximum measurements cited in the 
descriptions of these species pairs, the lengths of hamulus 1 are at least 4 times greater in the posterior site species than the anterior site species within the same host: 640 v. $110 \mu \mathrm{m}$; 680 v. $160 \mu \mathrm{m} ; 420$ v. $100 \mu \mathrm{m}$, respectively. Across these species pairs, sucker diameter is an overall average of $30 \%$ larger in species from the mouth/ pharynx than in those from the urinary bladder (Fig. 3).

Observations on living specimens show that the haptor is highly effective in attachment by suction, both to hard flat surfaces (such as glass) and to the flexible surface of host epithelial tissue. If a worm is subjected to strong water currents or pulled by forceps, the suckers typically slide rather than lose their grip. On a glass surface, attachment is presumably maintained principally by suction generated in each of the 6 muscular suckers, with the flange-like rim creating a seal and the dome of the sucker raised by muscular contraction to create negative pressure. Histological sections of suckers attached to host epithelium show that, in natural circumstances, a plug of host tissue is pulled into the hemispherical dome of the sucker and is gripped by the muscles surrounding the sucker opening. The marginal hooklet in the dome of each sucker impales the enclosed bladder wall and appears to resist movements that might pull the host tissue out of the hemisphere. Additionally, the 10 marginal hooklets situated antero-lateral and postero-medial to the suckers appear to pin down the edges of the haptor, while the recurved points of the hamuli further secure attachment by penetrating the superficial layers of epithelial cells. Although suction by the muscular suckers provides powerful adhesion on flat substrates, in vitro manipulations of worms attached to excised urinary bladder tissue demonstrate that haptoral suckers are vulnerable to detachment on highly contractile surfaces. If dissecting needles are inserted into the bladder wall on either side of the haptor and drawn quickly apart, the sudden change in surface area throws the suckers off the substrate. In life, the greater risk is created when a previously highly expanded surface suddenly contracts, disrupting the relative positions of the suckers and converting the flat bladder epithelium into irregular folds. However, in these circumstances, the points of the hamuli can remain embedded in host epithelium. The strength of this gaffing action is sufficient to maintain attachment even if all other points of contact are detached. During host urination, when bladder volume can change dramatically, this anchorage would reduce the immediate risk that the 
parasite is swept away from the attachment site and allows time (often requiring only a few seconds) for the suckers to regain their grip on the now-altered surface area.

\section{Geographical distribution}

The global distribution of the genus Polystomoides was mapped by Combes (1976) and Knoepffler and Combes (1977) for the then-known total of 22 species. Further aspects of zoogeography, particularly relating to Australasia, were discussed by Rohde and Pearson (1980); also, Morrison and Du Preez (2011) mapped a partial distribution of world records. Fig. 4 shows the current pattern including localities of several species inquirendae, unidentified specimens referred to Polystomoides sp., and geographical records additional to type localities (despite the present taxonomic confusion for some N. American Polystomoides spp., the original locality reports for these taxa remain valid). This data set produces a total of 68 records. Species infecting oral cavity sites in their chelonian hosts occur in N. America (USA and Canada); Central America (Mexico); South America (Brazil, Colombia, Uruguay); Europe (Spain, France, Italy, Germany, Poland, Ukraine, Russia, Romania, Bulgaria); North Africa bordering the Mediterranean (Morocco, Algeria, Tunisia); Asia bordering the Pacific (Japan, Taiwan, Philippines, Thailand, Malaysia). Species recorded in the urinary tract occur in Africa south of the Sahara (Senegal, Ghana, Togo, Nigeria, Uganda, Kenya); Madagascar; India; Asia bordering the Pacific (Japan, Taiwan, Thailand, Malaysia, Borneo); Australia. This virtually pan-global range is coincident with the worldwide distribution of the host group, the chelonian reptiles, but on present evidence no urinary tract species have been recorded in the Americas, Europe and N. Africa, and no oral cavity species are known from Africa south of the Sahara, Madagascar, India and Australia. On the other hand, there is significant overlap of ranges of the 2 parasite groups in S.E. Asia (Japan, Taiwan, Thailand, Malaysia) (Fig. 4).

\section{Molecular phylogeny}

Data relevant to this account are provided by 4 studies over nearly 20 years. Littlewood et al. (1997) analysed partial 28S rDNA and partial mitochondrial CO1 gene sequences (935 and 385 nucleotides respectively) for 2 Polystomoides species from the oral cavity and 2 species from the urinary tract (and also for 2 Neopolystoma species). Verneau et al. (2002) used 
partial 18S rDNA sequences in a wider phylogenetic analysis of 26 species of polystomatids of which 4 are relevant to this account: 3 Polystomoides species from the urinary tract and 1 species from the oral cavity (with this oral species and 2 of the urinary species the same as in the Littlewood et al. study). Olsen and Littlewood (2002) brought together all rDNA data then available in a phylogenetic analysis of the Monogenea using the same Polystomoides species as the 1997 study. Héritier et al. (2015) examined sequence data for 2 nuclear and 2 mitochondrial genes - rRNA 18S, 28S, CO1 and rRNA 12S - for a wide range of polystomatid species including 9 species (4 undescribed) of Polystomoides. While the previous studies had focused on Australian and Malaysian species, this latter survey also included species from North and West Africa and N. America.

All analyses are consistent in showing a profound separation of Polystomoides species in the 2 sites of infection. The data also indicate that the urinary tract species are monophyletic while Polystomoides species from the oral cavity have closer relationships with Neopolystoma than with Polystomoides from the urinary tract.

\section{DISCUSSION}

\section{Functional morphology}

The haptor of polystomatid monogeneans - a distinctive feature of this family in comparison with all other monogeneans - has never been investigated functionally with the level of detail applied to monogeneans of fish (as in the meticulous descriptions of Kearn, 1998, 2004). The mechanics of attachment by the hooks of monogeneans may have parallels with the principles reported for plant hooks (Chen et al. 2013). The mode of haptor function in Polystomoides has been considered in a few species descriptions (e.g. Stunkard, 1917; Pichelin, 1995). The present morphometric data, together with histological preparations and observations on living worms, indicate a major divergence in parasite evolution in which attachment organs are specialised for 2 contrasting sets of environmental constraints. For species in the 2 groups, in distinct sites of infection, there is no significant difference in parasite body size. However, the metrics of their major 
attachment structures - the suckers and hamuli - are highly significantly different with little or no overlap in either absolute or relative measurements. So, the 2 groups of species do not form part of a continuum in their morphological characters: they are distinct entities.

Expressed in diagnostic terms, the 2 groups are separated unambiguously by the relationship of hamulus 1 length to sucker diameter. In species infecting the oral cavity, the length of hamulus 1 is, on average, about one-quarter of sucker diameter and always less than half sucker diameter (range $9.8-43.5 \%$ ). In urinary tract species, hamulus 1 length is always greater than sucker diameter (up to more than twice the diameter) (range 129 $225 \%)$.

Considered in functional terms, the morphometric differences correlate with the microconditions at the infection sites. In anterior sites, including the mouth and nasal passages, the host epidermis forms a flat sheet that may slide over underlying structures, producing changes in surface area that are relatively smooth and gradual. In the pharynx, the muscular longitudinal folds of the gut wall may expand and contract (e.g. during food ingestion) but worms are typically protected between parallel ridges. In these anterior sites, worms are more-or-less exposed at the air-water interface and do not usually experience major forces from a surrounding liquid medium. In vivo studies confirm that attachment by muscular suckers is highly effective under these conditions and, should detachment occur, there is a reduced risk of loss from the infection site before suctorial attachment can be regained.

In posterior sites, including the urinary bladder, the host epithelium is highly contractile and sudden changes in surface area are typically accompanied by massive expulsion of the urine surrounding the worm. These additional detachment risks are countered by the gaffing of the host tissues by very large hamuli.

It can be expected that the mechanical stresses acting to detach a parasite (including sudden changes in habitat surface and liquid pressures) are proportional to worm body size (including body area, mass and resistance to the force of currents). A positive relationship would be predicted between attachment organ size (strength of attachment) and parasite size. Both groups of species, in oral and urinary sites, respond to increasing stress in 
equivalent ways: there is a similar strongly positive correlation between sucker diameter and body length suggesting that, in both groups, the increased demands of attachment in larger species are met to a major degree by increased adhesive capacity of larger suckers (Fig. 2). However, in oral species, sucker diameters are on average nearly $200 \mu \mathrm{m}$ bigger than in species infecting the urinary tract indicating a greater reliance on suctorial attachment in anterior sites.

The situation is reversed in the species specific to posterior sites. The continuing importance of the suckers is confirmed by the linear relationship between sucker diameter and body size but, in these species, the suckers are only about half the size of those in anterior site species (as a function of body length). The constraints affecting attachment here are influenced by the more unstable host epithelial surface and by the risk of expulsion by sudden, strong liquid flow. In these conditions, the hamuli may provide a major selective advantage, reflected in their much greater length. Hamulus 1 is typically nearly 4 times longer (relative to body length) in species from the urinary tract than in species from the oral cavity. In urinary tract species, both hamulus 1 and hamulus 2 show a linear increase in length suggesting both pairs of hamuli have a complementary role in attachment.

It might be considered that the allometric relationships noted (Fig. 2) simply reflect that bigger worms have bigger attachment organs. However, the influence of dynamic functional effects specific to parasite $x$ micro-habitat conditions is demonstrated by the data for the hamuli of oral cavity species. Counter-intuitively, for hamulus 1 , the slope of the relationship with body length is not significantly different from zero (Fig. 2B). So, in this infection site, the larger pair of hamuli makes no greater contribution to attachment as the presumed stress (or risk of detachment) produced by greater body size increases. In functional terms, this emphasises that the demands of attachment are met, in oral cavity parasites, by a dominant reliance on suctorial power (Fig. 2A), but the flat relationship could also have significance in evolutionary terms. The absence of a correlation between hamulus 1 and body size (Fig. 2B) could suggest that investment in hard tissues, the hamuli, is costly and production of larger structures that do not give greater advantage for attachment in oral sites has been selected against. 
The published data on hamulus length, employed in this analysis, reflect only part of the adaptation to site. The larger hamuli of urinary tract species characteristically have wide bases, expanded into wing-like plates, providing for much greater muscle attachment than the much slimmer hamuli of most oral cavity parasites (the species shown in Fig. 3 illustrate this comparison). This confirms the indications of considerably more powerful anchorage provided by the hamuli of posterior site species.

\section{Characteristics of larvae}

The oncomiracidia of polystomatid monogeneans have cilia-bearing cells on the tegument that enable the infective stage to swim and these are lost at the point of host invasion. The number of cells and their spatial distribution is characteristic for the polystomatid genera so far studied. Polystomatids infecting chelonians (except for the unstudied Polystomoidella) have 64 ciliated cells organised into 5 groups. Studies by Lambert and Kulo (1982) and Lambert et al. (1978) of Polystomoides species in North and West Africa have demonstrated 2 patterns of cell distribution: either all cells are separate from one another or some cells are conjoined with neighbouring cells. The pattern with separated cells occurs in Polystomoides species infecting the urinary bladder while conjoined cells occur in oral cavity species. The trait of separate cells is shared with the anuran parasite Protopolystoma while the trait of conjoined cells is shared with the mammal parasite Oculotrema (see Tinsley, 1981, 2013). Limited observations on Neopolystoma from N. America (Tinsley, 2013 and unpublished) show that ciliated cells are conjoined, suggesting a closer link to Polystomoides in oral sites than to urinary tract species (paralleling the relationships suggested by molecular phylogeny, see above). However, whilst it is tempting to link these larval characteristics to evolutionary relationships, the organisation reported in the few species studied elsewhere in the global distribution of Polystomoides is unclear (Tinsley, 2013); so, confirmation of the utility of cell patterns for distinguishing the 2 site-specific parasite lineages worldwide requires further investigation.

\section{Factors influencing geographical distribution}

The virtually worldwide distribution of the genus Polystomoides has been interpreted as archaic, reflecting an original occurrence on Pangaea during the early evolution of the 
Chelonia and subsequent dispersal with the present-day landmasses by plate tectonics (Rohde and Pearson, 1980).

The apparent absence of urinary tract Polystomoides species from the Americas, Europe and N. Africa and of oral cavity species from Africa south of the Sahara, Madagascar, India and Australia could be an artefact of research effort: it is likely that present records of Polystomoides represent only a fraction of actual species diversity. On the other hand, if a true reflection of distribution, these absences may reflect important evolutionary factors, including the chance failure of one of the parasite groups to expand into the respective areas before separation of the components of Pangaea (the concept of 'missed the boat'). Host migrations may also have been an important factor in present parasite distributions. The occurrence of urinary tract species alone in Africa, Madagascar, India and Australia corresponds with formerly-linked tectonic plates. Alternatively, one of the parasite lineages might have become extinct in a given region after initial occurrence. This could have been a consequence of host extinction: the fossil record since the Late Jurassic shows great diversity of chelonians from which only a fraction now survives (Crawford et al. 2015). Or, parasite lineages have become extinct in surviving host lineages. A range of factors make their life cycles, tied to transmission in water, vulnerable to environmental disturbance. Field and laboratory studies on anuran polystomatids have demonstrated the influence on parasite survival of environmental factors (especially prolonged drought and temperature change), host x parasite effects (especially powerful immune responses), and parasite $x$ parasite interactions (including inter-species interference and competitive exclusion) (e.g. Jackson et al. 1998, 2006; Tinsley, 1999, 2005). The outcome is reflected in very low exploitation by polystomatids of anuran populations (Tinsley, 1993). There is little equivalent information for polystomatids infecting chelonians, but population data (e.g. Strankowski, 1937; Rohde, 1965; Pichelin, 1995) typically show high prevalence (indicating effective host-to-host transmission) but very low intensities, mostly 1-3 worms/ host (suggesting powerful within-host regulation of parasites). By analogy with findings for anuran polystomatids, relatively small-scale perturbations in environmental conditions, especially temperature, could 'tip the balance' towards even lower intensities and, potentially, extinction (Tinsley, 2003, 2005). 
The possibility of antagonistic parasite $\mathrm{x}$ parasite interactions is suggested by the respective geographical distributions of Neopolystoma and Polystomoides. In regions where Polystomoides is absent from the host urinary tract - the Americas, Europe and N. Africa this infection site is occupied by a relatively rich diversity of Neopolystoma species. In parallel, the apparent absence of oral cavity Polystomoides from Australia coincides with infection here by (different) Neopolystoma species. Nevertheless, while competitive exclusion is a possible explanation, this situation could have occurred because Neopolystoma moved into vacant niches never exploited in these geographical regions by the respective Polystomoides lineages. Interpretation involving parasite interactions is confounded by the complexity of associations amongst chelonian polystomatids in Asia where Neopolystoma species infect the urinary tract, the oral cavity and the eyelid, overlapping with both site-specific groups of Polystomoides in Japan and Malaysia. This could indicate a different stage in evolution of the parasite interactions but overinterpretation of existing evidence would be premature.

The available data suggest no association between Polystomoides evolution and the diversification of the major lineages of Chelonia: the Cryptodira and Pleurodira. The apparent absence of specificity of Polystomoides species to host sub-orders, families or genera could be explained by lateral transfers between host groups: polystomatids appear less strictly host-specific to chelonians than to anuran amphibians. Thus, Pichelin (1995) reported laboratory cross-infections of $P$. australiensis between 2 host genera in Australia. Several studies have recorded host-switching of polystomatids between invasive and native species of chelonians in Spain, France and Japan (Hidalgo-Vila et al. 2009; Verneau et al. 2011; Oi et al. 2012; Meyer et al. 2015).

\section{Evidence of further fine-scale evolutionary divergence}

The present review of Polystomoides species indicates some regional differences in morphology potentially reflecting finer-scale relationships. Two evolutionary lines may be distinguished in the Americas. One is represented by a ' $P$. coronatus-type' widelydistributed in N. America (including several species regarded as synonyms of $P$. coronatus by Price, 1939) and in Mexico (e.g. Thatcher, 1963). This appears to have a 'pan-american' 
morphotype which several other N. American species resemble (including $P$. oris and $P$. pauli) and is represented in S. America by P. rohdei in Uruguay (Mañé-Garzón, 1958; MañéGarzón and Holcman-Spector, 1968) and P. magdalenensis in Colombia (Lenis and GarcíaPrieto, 2009). A second, very distinct, line is found, so far, in Uruguay and Brazil: P. fuquesi, P. uruguayensis and P. brasiliensis are unlike any other Polystomoides species in having deeply-divided hamuli and an exceptionally small complement of very short genital spines (Mañé-Garzón and Gil, 1961, 1962; Vieira et al. 2008). These features resemble those of polystomatids in anurans and caecilians rather than chelonians. This may be an isolated, perhaps archaic, lineage within oral cavity Polystomoides (perhaps with closer affinities to amphibian polystomatids). The hamulus 1 lengths in these $3 \mathrm{~S}$. American species are considerably shorter than those of all other Polystomoides species (producing outliers in Figs. 1,2) but they approach those of $P$. ocellatus, especially the specimens reported from Corsica by Knoepffler and Combes (1977). The N. American P. nelsoni (see Du Preez and Van Rooyen, 2015) also has major differences from all other species, including the very large number and length of its genital spines, suggesting another isolated line.

\section{Molecular phylogeny}

Each of the published molecular studies has confirmed the profound divergence between Polystomoides species infecting anterior and posterior sites within the host. Littlewood et al. (1997) showed that parasite species infecting the same site in different host species are more closely related than parasite species infecting the same host species but occupying different sites. The data in Figure 1 of Héritier et al. (2015) show that urinary tract species from Africa and Malaysia are more closely related to each other than either is to the species infecting oral sites in these 2 geographically distant regions. In reciprocal agreement, Polystomoides species specific to the oral cavity in Malaysian hosts are more closely related to oral cavity parasites in Africa than they are to bladder parasites in Malaysia. This is an exact parallel to the scenario investigated by Littlewood et al. (1997) but at the scale of separate continents rather than host species. These and other data also exclude the possibility that the worldwide occurrence of 2 Polystomoides morphotypes reflects convergent evolution of unrelated parasites in response to the same selection pressures in the respective habitats. 
The zoogeographical and molecular studies provide a guide to the age of the split within Polystomoides. Rohde and Pearson (1980) considered that the present world-wide distribution of chelonian polystomatids reflects an ancient origin before the break-up of Pangaea, close to 200 Mya, while Sinnappah et al. (2001) suggested an even earlier origin. Molecular chronologies have produced a range of estimates depending on assumptions. Verneau et al. (2002) calculated that chelonian polystomatids radiated ca. $191 \pm 40$ Mya. Héritier et al. (2015) considered 2 possibilities for the origin: ca. 178 or 152 Mya depending on hypotheses of host-switching. Estimates of the timing, during the host and parasite radiations, at which a proto-Polystomoides diverged into lineages specific to anterior and posterior sites of infection, are conjectural. Figure 2 of Héritier et al. (2015) shows a divergence time estimate between urinary Polystomoides and other chelonian polystomatids of $131 \mathrm{My}$ (although based on only 4 species from 2 geographical regions, and with wide confidence limits). This range is still consistent with an association with the break-up of Pangaea and Gondwanaland, given the extended timing of separation of constituent parts of the supercontinent. De Baets et al. (2015) discussed the complications of dating parasite divergences from molecular clocks and vicariance events, including the dangers of circularity in arguments. For the present account, estimating a specific date for the Polystomoides dichotomy is unnecessary: the available evidence is sufficient to conclude that separation of anterior and posterior site lineages is ancient, probably since the Jurassic or, at the latest, the Jurassic/Cretaceous boundary.

\section{Implications for the systematics of Polystomoides: recognition of generic separation}

The main principles considered in this account have been established in a series of independent studies over the past 50 years, beginning with emphasis on site-specific morphological divergence (see Introduction). Molecular findings (above) that the lineage of Polystomoides species infecting the urinary tract is monophyletic confirm the profound separation from oral cavity species which have closer affinities with Neopolystoma. All lines of evidence combine to support the original proposal by Tinsley $(1971$, loc. cit.) that the separation of the 2 lineages should be recognised with distinct generic status. Regarding nomenclature, the type species of the genus Polystomoides is $P$. coronatus (Leidy, 1888) Ozaki, 1935, so this generic name is restricted to species from the oral cavity and associated 
anterior sites. We propose that species in the urinary tract are assigned to a new genus, Uropolystomoides $\mathrm{n}$. gen., with the appellation referring to the site of infection which is diagnostic for chelonian polystomatids with 2 pairs of hamuli. The earliest description in the urinary tract lineage - kachugae - is incomplete (Stewart, 1914) and this species has not since been recorded. The type species selected - Uropolystomoides chabaudi, originally described by Euzet and Combes (1965) - belongs to a well-studied group of African posterior-site species and has morphometric characters close to average for the lineage worldwide (except for relatively smaller body size). A formal definition of the new genus and a list of species in the 2 lineages is presented in Appendix 1.

\section{Conclusions}

Creation of the genus Uropolystomoides recognises a clade that has probably been distinct since the Jurassic. Polystomatid monogeneans have evolved in parallel with vertebrates and present-day representatives show very considerable diversity in morphological designs. This variation is illustrated, first, by the major differences within the largest group, those infecting anurans (e.g. Tinsley, 1983), and second, by the highly divergent body plan of the mammalian parasite Oculotrema hippopotami (see Introduction) that differs from other polystomatids in all or almost all aspects of morphology (Table 1 in Tinsley, 2013). However, for the second largest group of polystomatids, the genera Neopolystoma, Polystomoidella, Polystomoides and Uropolystomoides infecting chelonians, there is a complete contrast. All species have a highly simplified organisation of the gut, ovary, testis, vitellaria and associated ducts and, in contrast to anuran polystomatids, the arrangement of these organs is strikingly uniform. It seems unlikely that this simple plan was arrived at independently from previously disparate morphotypes throughout a worldwide distribution. It is more parsimonious to consider that this was the basic plan for all lineages of chelonian polystomatids (at least those with known survivors) at the time of their evolution during the Jurassic. So, it is reasonable to conclude that in Polystomoides/Uropolystomoides, the morphotypes evident now throughout the virtually global distribution of these parasites have diverged in only one major character, in haptor morphology. This adaptation to sitespecific differences in habitat conditions must have already been established before or early in the break-up of Pangaea. 
582 For most modern reconstructions of parasite phylogeny, there is often a strong indication of 583 what specific molecules were like in ancestral forms but no real guide to the appearance of 584 the worms themselves. The sequential morphological changes leading to extant 585 platyhelminths are, typically, largely unknown. The present case study of polystomatids 586 infecting chelonians is exceptional and leads to two reciprocal conclusions. First, the two 587 genera Polystomoides/Uropolystomoides probably achieved their present state in deep

588 evolutionary time and their body plan has remained essentially unchanged over the 589 enormous time period since. Second, for a parasite group without any fossil record, it is 590 possible to conclude with a high degree of probability what ancestors looked like in the 591 Jurassic - almost certainly much like present-day forms. The extant forms are, indeed, 592 'living fossils'. Put into wider perspective, this long period of morphological stasis begins 593 before the diversification of the mammals and, hence, the huge diversification of all 594 mammalian parasites.

597 The initial studies by RCT were supported by a postgraduate studentship from the then 598 Science Research Council, U.K. 
601 Bychowsky, B.E. (1957). Monogenetic trematodes, their classification and phylogeny.

602 Academy of Sciences, U.S.S.R. Moscow and Leningrad (in Russian). English Translation by

603 Hargis, W.J. and Oustinoff P.C. (1961). American Institute of Biological Sciences, Washington.

604 Chen, Q., Gorb, S.N., Gorb, E. and Pugno, N. (2013). Mechanics of plant fruit hooks. Journal of

605 the Royal Society Interface 10, 20120913.

606 Combes, C. (1976). [World biogeography of polystomatid monogeneans. In memoriam of B.E.

607 Bykhovskii..] (in Russian) Trudy Biologo - Pochvennogo Instituta (Issle dovaniya

608 monogenehcheskikh sasal'shchikov) Novaya Senaya 34 (137), 55-69.

609 Crawford, N.G., Parham, J.F., Sellas, A.B., Faircloth, B.C., Glenn, T.C., Papenfuss, T.J.,

610 Henderson, J.B., Hansen, M.H. and Simison, W.B. (2015). A phylogenomic analysis of turtles.

611 Molecular Phylogenetics and Evolution 83, 250-257.

612 De Baets, K. and Littlewood, D.T.J. (2015). The importance of fossils in understanding the

613 evolution of parasites and their vectors. Advances in Parasitology 90, 1-51.

614 De Baets, K., Dentzien-Dias, P., Upeniece, I., Verneau, O. and Donoghue, P.C.J. (2015).

615 Constraining the deep origin of parasitic flatworms and host-interactions with fossil evidence.

616 Advances in Parasitology 90, 93-135.

617 Du Preez, L. H. and Van Rooyen, M. (2015). A new polystomatid (Monogenea,

618 Polystomatidae) from the mouth of the North American freshwater turtle Pseudemys nelsoni.

619 ZooKeys 539, 1-9.

620 Euzet, L. and Combes, C. (1965). Polystomoides chabaudi n. sp (Monogenea) chez la tortue

621 d'eau douce Pelomedusa subrufa Lacépede 1788. Annales de Parasitologie Humaine et

622 Comparée 40, 455-450. 
623 Fairfax, R.A. (1990). A new species of Neopolystoma (Monogenea) and the occurrence of 624 Polystomoides sp. in New Guinea, with notes on some polystomes from North-East Australia.

625 Science in New Guinea 16, 109-114.

626 Fischthal, J.H. and Kuntz, R.E. (1964). A monogenetic and seven digenetic trematodes of 627 amphibians and reptiles from Palawan Island, Philippines. Proceedings of the Helminthological 628 Society of Washington 31, $230-240$.

629 Fukui, T. and Ogata, T. (1936). Sur deux espèces nouvelles de trématode provenant de 630 I'Ocadia sinensis. Zoological Magazine, Tokyo 48, 765-770.

631 Fukui, T. and Ogata, T. (1939). On three species of trematodes from Ocadia sinensis (Gray). 632 Volume Jubilare pro Prof. S. Yoshida 2, 187-202.

633 Gupta, N.K. and Randev, R. (1974). On the histomorphology of Polystomoides ludhianae n. sp. 634 (Monogenea) recovered from the urinary bladder of Kachuga tectum and Kachuga smithi in 635 North India. Parassitologia 16, 225-229. Héritier, L., Badets, M., Du Preez, L.H., Aisien, M.S.O., Lixian, F., Combes, C. and Verneau, 0. 637 (2015). Evolutionary processes involved in the diversification of chelonian and mammal 638 polystomatid parasites (Platyhelminthes, Monogenea, Polystomatidae) revealed by 639 palaeoecology of their hosts. Molecular Phylogenetics and Evolution 92, 1-10. Hidalgo-Vila, J., Díaz-Paniagua, C., Ribas, A., Florencio, M., Pérez-Santigosa, N. and Casanova, J.C. (2009). Helminth communities of the exotic introduced turtle, Trachemys scripta elegans in 642 southwestern Spain: transmission from native turtles. Research in Veterinary Science 86, 463643465.

644 Jackson, J.A., Tinsley, R.C. and Hinkel, H. (1998). Mutual exclusion of congeneric monogenean 645 species in a space-limited habitat. Parasitology 117, 563-569. 

$648 \quad$ 1341-1349.

649

Jackson, J.A., Pleass, R.J., Cable, J., Bradley, J.E. and Tinsley, R.C. (2006). Heterogeneous interspecific interactions in a host-parasite system. International Journal for Parasitology 36,

Kearn, G.C. (1998). Parasitism and the platyhelminths. Chapman and Hall, London, U.K.

Kearn, G.C. (2004). Leeches, lice and lampreys. A natural history of skin and gill parasites of fishes. Springer, Dordrecht, Netherlands.

Knoepffler, L-P. and Combes, C. (1977). Présence en Corse de Polystomoides ocellatum (Rudolphi, 1819) chez Emys orbicularis (L., 1758) (Chelonia, Emydidae). Considérations sur la répartition mondiale du genre Polystomoides. Vie Milieu 27, 221-230.

Lambert, A. and Kulo, S. D. (1982). Existence d'une dualité morphologique chez

I'oncomiracidium de Polystomoides nabedei Kulo, 1980. Annales de Parasitologie Humaine et Comparée 57, 237-243.

Lambert, A., Combes, C. and Ktari, M.H. (1978). Morphologie de l'oncomiracidium de Polystomoïdes Ward, 1917 (Monogenea) et situation du genre parmi les Polystomatidae. Zeitschrift für Parasitenkunde 56, 175-181.

Leidy, J. (1888). Entozoa of the terrapin. Proceedings of the Academy of Natural Sciences, Philadelphia 40, 127-128.

Lenis, C. and García-Prieto, L. (2009). Polystomoides magdalenensis n. sp. (Monogenoidea: Polystomatidae), a parasite of buccal cavity of Trachemys callirostris callirostris (Testudinata: Emydidae) from Colombia. Journal of Parasitology 95, 850-854. Leung, T.L.F. (2016). Fossils of parasites: what can the fossil record tell us about the evolution of parasitism? Biological Reviews (in press) [doi: 10.1111/brv.12238] 
668 Littlewood, D.T.J., Rohde, K. and Clough, K.A. (1997). Parasite speciation within or 669 between host species? - Phylogenetic evidence from site-specific polystome 670 monogeneans. International Journal for Parasitology 27, 1289-1297.

Mañé-Garzón, F. (1958). Sobre el hallazgo de Polystomoides coronatus (Leidy, 1888) en la boca 672 de una tortuga de Sudamérica. Revista de Medicina Veterinaria y Parasitología, Maracay 18, $673 \quad 35-41$. Mañé-Garzón, F. and Gil, O. (1961). Trematodos de las tortugas del Uruguay, I. Una nueva especie del genero Polystomoides Ward 1917, de la cavidad bucal de Phrynops geoffroana hillarii (D. \& B.). Comunicaciones Zoologicas del Museo de Historia Natural de Montevideo 5, 16774.

Mañé-Garzón, F. and Gil, O. (1962). Trematodos de las tortugas del Uruguay, V. Sobre un nuevo Polystomatidae de la faringe de Phrynops geoffroana hillarii (D. \& B.). Comunicaciones Zoologicas del Museo de Historia Natural de Montevideo 7, 1-6.

Mañé-Garzón, F. and Holcman-Spector, B. (1968). Trematodos de las tortugas del Uruguay, VII. Polystomoides rohdei n. sp. de la boca de Pseudemys dorbigni (Dum. \& Bib.). Comunicaciones Zoologicas del Museo de Historia Natural de Montevideo 9, 1-3. Meyer, L., Du Preez, L., Bonneau, E., Héritier, L., Quintana, M.F., Valdeón, A., Sadaoui, A., Kechemir-Issad, N., Palacios, C. and Verneau, O. (2015). Parasite host-switching from the invasive American red-eared slider, Trachemys scripta elegans, to the native Mediterranean pond turtle, Mauremys leprosa, in natural environments. Aquatic Invasions 10, 79-91. Morrison, C. and Du Preez, L. (2011). Turtle polystomes of the world. Neopolystoma, Polystomoidella \& Polystomoides. VDM Verlag Dr. Muller, Saarbrücken, Germany. 
690

691

692

693

694

695

696

697

698

699

700

701

702

703

704

705

706

707

708

709

710 711 harnblase von Cyclemys amboinensis in Malaya. Zeitschrift für Parasitenkunde 22, 278-282.

Oi, M., Araki, J., Matsumoto, J. and Nogami, S. (2012). Helminth fauna of a turtle species introduced in Japan, the red-eared slider turtle (Trachemys scripta elegans). Research in Veterinary Science 93, 826-830.

Olsen, P.D. and Littlewood, D.T.J. (2002). Phylogenetics of the Monogenea - evidence from a medley of molecules. International Journal for Parasitology 32, 233-244.

Ozaki, Y. (1936). Two new trematodes from tortoise Geoemyda spengleri (Gmelin). Journal of Science of the Hiroshima University, Series B 4, 85-90.

Pandey, K.C. (1973). Studies on monogenetic trematodes of India, II. On a new species of the rare genus Polystomoides Ward, 1917. Indian Journal of Zootomy 14, 143-145.

Pandey, K.C. and Agarwal, N. (1978). A new monogenean, Polystomoides chauhani n.sp., from Hardella thurgi Gray. Indian Journal of Helminthology 30, 126-128.

Pichelin, S. (1995). The taxonomy and biology of the Polystomatidae (Monogenea) in Australian freshwater turtles (Chelidae, Pleurodira). Journal of Natural History 29, 1345-1381.

Price, E.W. (1939). North American monogenetic trematodes. IV. The family Polystomatidae (Polystomatoidea). Proceedings of the Helminthological Society of Washington 6, 80-94.

R Development Core Team (2016). R: A language and environment for statistical computing. R Foundation for Statistical Computing, Vienna, Austria.

Rao, S.L. (1975). On two monogenetic trematodes from the urinary bladder of Kachuga tectum tentora Gray (Family Polystomatidae Gamble, 1896). Rivista di Parassitologia 36, 261266.

Rohde, K. (1963). Polystomoides malayi n. sp. (Monogenea, Polystomatidae) aus der 
712 Rohde, K. (1965). Studies on the genus Polystomoides Ward, 1917 (Monogenea). I. Description

713 of 4 Malayan species, a key to the known species, and a comparison of the subcuticular layer in

714 Polystomoides and some digenetic trematodes. Zoologische Jahrbücher Abteilung für

715 Systematik, Ökologie und Geographie der Tiere 92, 345-368.

716 Rhode, K. (1984). Three new species of the genus Neopolystoma (Monogenea) from river

717 tortoises in Australia. Systematic Parasitology 6, 99-105.

718 Rohde, K. and Pearson J.C. (1980). Two polystomes (Monogenea) from Australian river

719 tortoises (Pleurodira, Chelidae), Polystomoides australiensis sp. nov. from Emydura krefftii, and

720 Neopolystoma chelodinae (MacCallum, 1919) from Chelodina longicollis. Zoologischer Anzeiger

$721 \quad 204,191-208$.

722 Sinnappah, N.D., Lim, L.H.S., Rohde, K., Tinsley, R., Combes, C. and Verneau, O. (2001).

723 A paedomorphic parasite associated with a neotenic amphibian host: phylogenetic

724 evidence suggests a revised systematic position for Sphyranuridae within anuran and

725 turtle polystomatoineans. Molecular Phylogenetics and Evolution 18, 189-201.

726 Sproston, N.G. (1946). A synopsis of the monogenetic trematodes. Transactions of the

727 Zoological Society of London 25, 185-600.

728 Stewart, F.H. (1914). Studies in Indian Helminthology 11. The anatomy of Polystomum

729 kachugae, sp. nov., with notes on the genus Polystomum. Records of the Indian Museum 10,

$730 \quad 195-205$.

731 Strankowski, M. (1937). Recherches anatomiques sur Polystoma ocellatum Rud. Zoologica

732 Poloniae 2, 1-20.

733 Stunkard, H. (1917). Studies on North American Polystomidae, Aspidogastridae, and

734 Paramphistomidae. Illinois Biological Monographs 3, 285-385. 
735 Thatcher, V.E. (1963). Trematodes of turtles from Tabasco, Mexico with a description of a new 736 species of Dadaytrema (Trematoda: Paramphistomidae). American Midland Naturalist 70, 347-

737355.

738 Timmers, S.F. and Lewis, P.D. (1979). Helminths of Chrysemys picta belli in Manitoba including

739 Polystomoides pauli sp. n. (Monogenea: Polystomatidae). Canadian Journal of Zoology 57,

$740 \quad 1046-1051$.

741 Tinsley, R.C. (1981). The evidence from parasite relationships for the evolutionary status of

742 Xenopus (Anura Pipidae). Monitore zoologico italiano N.S. Supplemento 15, 367-385.

743 Tinsley, R.C. (1983). Ovoviviparity in platyhelminth life cycles. Parasitology 86, 161-196.

744 Tinsley, R.C. (1990). Host behaviour and opportunism in parasite life cycles. In

745 Parasitism and host behaviour (eds. Barnard C.J. and Behnke J.), pp. 158-192. Taylor and

746 Francis, London, UK.

747 Tinsley, R.C. (1993). The population biology of polystomatid monogeneans. Bulletin Français

748 de la Pêche et de la Pisciculture 328, 120-136.

749 Tinsley, R.C. (1999). Parasite adaptations to extreme conditions in a desert environment.

750 Parasitology 119, S31-56.

751 Tinsley, R.C. (2003). Polystomatid monogeneans and anuran amphibians: an evolutionary arms

752 race leading to parasite extinctions? In Taxonomie, écologie et évolution des métazoaires

753 parasites (eds. Combes, C. and Jourdane J.), pp. 259-285. Presses Universitaires de Perpignan,

754 Perpignan, France.

755 Tinsley, R. C. (2004). Platyhelminth parasite reproduction: some general principles derived

756 from monogeneans. Canadian Journal of Zoology 82, 270-291. 
Tinsley, R. C. (2005). Parasitism and hostile environments. In Parasitism and Ecosystems (eds. Thomas, F., Renaud, F. and Guégan, J-F.), pp. 85-112. Oxford University Press, Oxford. Tinsley, R.C. (2013). The oncomiracidium of Oculotrema hippopotami Stunkard, 1924 and relationships within the Polystomatidae (Monogenea). Systematic Parasitology 84, 123-135. Tinsley, R.C., York, J.E., Stott, L.C., Everard, A.L.E., Chapple, S.J., Tinsley, M.C. (2011). Environmental constraints influencing survival of an African parasite in a north temperate habitat: effects of temperature on development within the host. Parasitology 138, 1039-1052. Verneau, O., Bentz, S., Sinnappah, N.D., Du Preez, L., Whittington, I. \& Combes, C. (2002). A view of early vertebrate evolution inferred from the phylogeny of polystome parasites (Monogenea: Polystomatidae). Proceedings of the Royal Society, London B 269, 535-543.

Verneau, O., Palacios, C., Platt, T., Alday, M., Billard, E., Allienne, J.-F., Basso, C. and Du Preez, L.H. (2011). Invasive parasite threat: parasite phylogenetics reveals patterns and processes of host-switching between non-native and native captive freshwater turtles. Parasitology 138, 1778-1792.

Vieira, F. M., Novelli, I.A., Sousa, B.M. and de SouzaLima, S. (2008). A new species of Polystomoides Ward, 1917 (Monogenea: Polystomatidae) from freshwater chelonians (Testudines: Chelidae) in Brazil. Journal of Parasitology 94, 626-630.

Ward, H.B. (1917). On the structure and classification of North American parasitic worms. Journal of Parasitology 4, 1-13. 
779

780

781

782

783

784

785

786

787

788

789

790

791

792

793

794

795

796

797

798

799

800

801

802

803

804

805

806

807

808

809

810

811

812

813

814

815

816

\section{Taxonomy}

Family: $\quad$ Polystomatidae Gamble, 1896

Subfamily: Polystomoidinae Yamaguti, 1963, amended Pichelin, 1995.

Genus: $\quad$ Polystomoides Ward, 1917

The generic diagnosis of Ward (1917), defined by Price (1939) and amended by Pichelin (1995), is restricted here to species that infect anterior sites in chelonian hosts - the oral, nasal and pharyngeal tracts - and have a haptor with hamuli that are short relative to sucker diameter (length of the larger, outer pair of hamuli (hamulus 1 in this account) typically less than half the diameter of the suckers).

\section{Genus: $\quad$ Uropolystomoides gen. nov.}

Most diagnostic characters as for Polystomoides following Pichelin (1995), but distinguished from Polystomoides sensu stricto (this account) by posterior sites of infection - urinary bladder, accessory bladders and cloaca - and haptoral hamuli that are long relative to sucker diameter (length of hamulus 1 always greater than sucker diameter).

Generic diagnosis. Polystomatidae. Polystomoidinae. Haptor with 2 pairs of long, robust hamuli: lengths of larger, outer pair (hamulus 1) greater than sucker diameter. Haptoral suckers with type 2 morphology (following Pichelin, 1995; c.f. Stunkard, 1917). Mouth subterminal with false oral sucker and bucco-oesophageal canal. Pharynx muscular, oesophagus short or absent. Intestinal caeca paired, lateral, usually extending length of body, not entering haptor, with or without diverticula, confluent or not posteriorly; gut contents typically colourless or white (without dark pigment). Testis single, compact, in mid-body; seminal vesicle present; genital bulb with coronet of spines. Ovary anterior to testis, lateral to mid-line. Vitelline follicles generally extending along gut caeca, confluent in mid-body posterior to testis or in separate lateral fields. Vaginae present. Oötype containing a single large egg without appendage. Uterus absent. Oncomiracidia with 64 ciliated cells. Parasitic in urinary tract (urinary bladder and accessory bladders, cloaca, sometimes kidneys and kidney ducts) of freshwater chelonians.

Type species: Uropolystomoides chabaudi (Euzet and Combes, 1965).

Etymology: Reference to site of infection - the urinary tract - provides unambiguous separation from Polystomoides sensu stricto whose species infect anterior sites in the host's gut/ respiratory tract. 


\section{Genus Polystomoides Ward, 1917 (amended)}

820

Type species: $P$. coronatus' (Leidy, 1888)

822 Other species:

823 P. asiaticus Rohde, 1965

824 P. brasiliensis Vieira, Novelli, Sousa \& de SousaLima, 2008

825 P. cyclemydis Fischthal \& Kuntz, 1964

$826 \quad P$. fuquesi Mañé-Garzón \& Gil, 1962

827 P. japonicust Ozaki, 1935

828 P. magdalenensis Lenis \& García-Prieto, 2009

829 P. microrchis Fukui \& Ogata, 1936

$830 \quad$ P. multifalx (Stunkard, 1924)

831 P. nelsoni Du Preez \& Van Royen, 2015

$832 \quad P$. ocellatust (Rudolphi, 1819)

833 P. oris Paul, 1938

$834 \quad$ P. pauli Timmers \& Lewis, 1979

835 P. platynotae Combes \& Rohde, 1978

$P$. renschi Rodhe, 1965

P. rohdei Mañé-Garzón \& Holcman-Spector, 1968

P. tunisiensis Gonzales \& Mishra, 1977

P. uruguayensis Mañé-Garzón \& Gil, 1961

Genus: Uropolystomoides $\mathbf{n}$. gen.

839 Other species:

840 U. australiensis (Rohde \& Pearson, 1980) n. comb.

$841 U$. bourgati (Combes \& Kulo, 1978) n. comb.

842 U. chauhani* (Pandey \& Agarwal, 1978) n. comb.

843 U. kachugae (Stewart, 1914) n. comb.

844 U. ludhianae (Gupta \& Randev, 1974) n. comb.

845 U. malayi (Rohde, 1963) n. comb.

846 U. megaovum* (Ozaki, 1936) n. comb.

847 U. nabedei (Kulo, 1980) n. comb.

$848 \quad U$. ocadiae (Fukui \& Ogata, 1936) n. comb.

$849 U$ U. scottae (Pichelin, 1995) n. comb.

850 U. siebenrockiellae (Rohde, 1965) n. comb.

851 U. stewarti* (Pandey, 1973) n. comb. 
The list may include some species that are synonyms of pre-existing taxa and others that comprise multiple species (see Appendix 2). +Species names follow Sproston (1946) for grammatical agreement. ${ }^{*}$ Not included in the data analysis because of omission or uncertainty of measurements in the original descriptions (Appendix 2); nevertheless, the published diagrams give conclusive confirmation of generic diagnosis.

\section{Methodological approach}

a) Morphometric measurements. The data set of published species descriptions has several factors influencing its use in this study. Infection levels of polystomatids are, with few exceptions, very low (Tinsley, 1993) and sample sizes reported in most taxonomic accounts are almost always small: some based on a single specimen. Some accounts report morphometrics for larger samples only as the maximum observed (measurements cited as 'up to ...'). For these species, therefore, the data available for analysis are unavoidably based on sample sizes of one (the outcome for nearly half of the species). Typically, developing juvenile stages of polystomatids have attachment structures, including the haptor and suckers, that are larger relative to body size than in fully-developed worms (see, for instance, the developmental sequence in Tinsley et al. 2011). Published descriptions that include measurements from immature worms could therefore produce skewed character ranges. To avoid this, the data employed in this study have been restricted to adults (where these have been distinguished). In descriptions where maturity in samples of worms is not specified and where wide measurement ranges are cited, it could be unrepresentative to employ means calculated from the maximum and minimum extremes. In view of these various limitations, the present analysis is based on the maximum (or sole) measurement for the given characters cited in the species descriptions. This has the advantage that the species metrics were generally based on the dimensions of an actual worm rather than data artificially generated (and potentially biased) by calculation of means with uncertain limitations.

b) Species considered. The recent literature (e.g. Morrison and Du Preez, 2011) lists a total of 38 species of Polystomoides but there is much confusion regarding the validity of some species. It might be expected that species descriptions published during more than 100 years may be influenced by variations in methodology (including potential fixation-induced effects), precision of measurements and extent of detail. Three valid species have been omitted from the present analyses. The description of $P$. megaovum by Ozaki (1936) provides no measurements for the 2 pairs of hamuli. The accounts of $P$. stewarti and $P$. chauhani have measurements in the text that are not consistent with dimensions depicted in the scale diagrams (Pandey, 1973; Pandey and Agarwal, 1978, respectively). In addition to these, 3 species from India, P. Iudhianae, $P$. simhai and $P$. godavarii, all from the same 
892

893

894

895

896

897

898

899

900

901

902

903

904

905

906

907

908

909

910

911

912

913

914

915

916

917

918

919

920

921

922

923

924

925

926

927

928

929

930

host species (Gupta and Randev, 1974; Rao, 1975), are presumed in this account to be conspecific (in agreement with Rohde and Pearson, 1980): P. ludhianae is listed here as the valid name.

Some problems arise from uncertainties over parasite and host identities. Authorities including Pichelin (1995) have considered that the descriptions of some polystomatid taxa may include other cryptic or presently-undefined species. Rohde (1984) recorded uncertainty over the identification of some Australian chelonian hosts; Fairfax (1990) questioned whether certain hosts should be better regarded as distinct species or subspecies or members of a cline. Where a single Polystomoides species has been described from several host species, it is possible that the morphological data recorded relate to more than one parasite taxon. The use in this account of a single individual as representative of a species (above) avoids these potential problems.

A conservative approach has been adopted with the confused record of N. American Polystomoides species: from the older literature, only $P$. oris, $P$. coronatus and $P$. multifalx have been included. Stunkard (1917) cited the metrics for the type specimen of $P$. coronatus described by Leidy (1888) so these are used as authentic data for the species. Price (1939) was probably not justified in relegating 5 previously-described species to synonymy with P. coronatus (see Bychowsky, 1957; Rohde, 1965; Timmers and Lewis, 1979): these require further critical study. Price cites measurements for his single taxon ' $P$. coronatus' (without specifying the source of these data) but there are major differences from the type of Stunkard (and Leidy). At least 2 distinct taxa may be represented and both sets of metrics are included in this account (using the maximum dimensions from the account of Price).

Two entries are included for $P$. ocellatus since the data for material from Poland and Corsica (Strankowski, 1937; Knoepffler and Combes, 1977, respectively) appear to have fundamental differences (including genital hooklet size) that may reflect species divergence.

Polystomoides cyclemydis was originally reported from the large intestine of its host (Fischthal and Kuntz, 1964), an aberrant infection site. The attachment metrics fit within the distinctive range typical of Polystomoides species from the oral cavity (noted also by Rohde and Pearson, 1980); so these data are included within the 'oral' series in the present analysis. Polystomoides magdalenensis was recorded in the buccal cavity of 52 host individuals but 'incidentally in cloaca' of one host (Lenis and García-Prieto, 2009). This must reflect the possibility of displacement along the alimentary tract, perhaps following accidental detachment from the normal anterior site. 
c) Data analysis. Various alternative approaches to determining relationships of attachment structures were tested in this study. Sucker diameter provides a proxy for power of suctorial attachment but sucker area may be more representative of function: so, the square of diameter may give a more informative measure. Analyses were therefore repeated using diameter squared but this did not improve the fit to the data. The analyses also tested whether the relationships between attachment organ size and body length were linear or curved by assessing the fit of models including polynomial body size terms; these models confirmed the relationships were linear. Worm body length introduces uncontrolled variation in the data set since it is the metric most likely to be influenced by pressure during fixation of whole-mount preparations: the effects on calculation of relationships may act in opposite directions or may be additive. For species comparisons, the present approach to employ maximum dimensions cited in the original descriptions may give unrealistic weight to extreme metrics. The description of $P$. ludhianae cites a maximum body length $(>10 \mathrm{~mm})$ that is very considerably larger than all other Polystomoides species (see Gupta \& Randev, 1974). Hamulus length in $P$. kachugae is exceptional amongst all species: the measurement - '0.9mm' - cited by Stewart (1914) for a single specimen may lack precision. Maximum sucker diameter cited for $P$. brasiliensis (apparently for a single sucker rather than the average for a single worm) is about $30 \%$ greater than the next largest record (which is for a larger species) (see Vieira et al. 2008). Uncertainties such as these about fair representation of species characters may explain some of the outliers in the data analyses and figures above. Analyses have therefore been repeated omitting these extreme records but the statistical relationships are so strong that comparisons between the groups of species remain conclusive. 
Fig. 1. Relationships of hamulus and sucker sizes in polystomatids (species of Polystomoides sensu stricto) from anterior infection sites (oral, pharyngeal, nasal tracts) in their chelonian hosts compared with species from posterior sites (urinary tract) (designated here Uropolystomoides n. gen.). Sample sizes: oro-nasal tract species $n=20$ (dark grey bars), urinary tract species $n=12$ (light grey bars); intermediate shading identifies regions where distributions overlap. $t$-tests demonstrated significant attachment organ size differences between species inhabiting the 2 infection sites for all metrics: $(A)$ hamulus 1 size $\left(t_{(d f=11.6)}=\right.$ 6.918, $P<0.0001),(B)$ hamulus 2 size $\left.\left(t_{(d f}=11.6\right)=5.499, P<0.0002\right),(C)$ sucker diameter $\left(t_{(d f}=\right.$ $22.5)=2.998, P=0.0065)$, (D) hamulus 1 size relative to body length $\left(t_{(d f}=14.4\right)=10.373$, $P<0.0001)$, (E) hamulus 2 size relative to body length $\left(\mathrm{t}_{(\mathrm{df}=13.1)}=7.211, P<0.0001,(\mathrm{~F})\right.$ sucker size relative to body length $\left.\left(t_{(d f}=28.5\right)=6.599, P<0.0001\right)$.

Fig. 2. Relationships between attachment organ size and body size in species of Polystomoides sensu stricto from the oro-nasal tract (dark grey, $\mathrm{n}=20$ ) and species of Uropolystomoides $\mathrm{n}$. gen. in the urinary tract (light grey, $\mathrm{n}=12$ ) of their chelonian hosts. Best fit lines and shaded 95\% confidence regions are derived from linear models (see text). The allometric slopes do not differ between oro-nasal and urinary tract species for sucker diameter $(A)$, but are significantly different for hamulus $1(B)$ and hamulus 2 lengths $(C)$, see text for statistics.

Fig. 3. Comparison of haptoral attachment structures in 3 examples where a single chelonian host species carries polystomatid species in both the posterior (urinary bladder) and anterior (oral cavity/ pharynx) infection sites. For each parasite species, data from the original taxonomic descriptions drawn to the same scale show relative sizes of the haptoral suckers and 2 types of hamuli (the larger hamulus 1 and smaller hamulus 2). Horizontal comparisons ( 2 parasite species in the same host species) show that the length of hamulus 1 is >twice sucker diameter in bladder parasites and <half sucker diameter in oral cavity/ pharynx parasites. Vertical comparisons (parasite species in the same infection site) show 
985 that the hamuli are characteristically large and robust, providing powerful muscle 986 attachment and a strong gaffing action, in bladder parasites (designated Uropolystomoides

987 n. gen.). Hamuli are small and slender in anterior site species (Polystomoides sensu stricto in 988 this account) suggesting a relatively minor contribution to attachment alongside a greater 989 role of the larger muscular suckers.

990

991 Fig. 4. Global distributions of species of Polystomoides sensu stricto (+) infecting anterior 992 sites (oral, pharyngeal, nasal tracts) and Uropolystomoides n. gen. (x) infecting posterior 993 sites (urinary tract) of freshwater chelonians, based on literature records. 

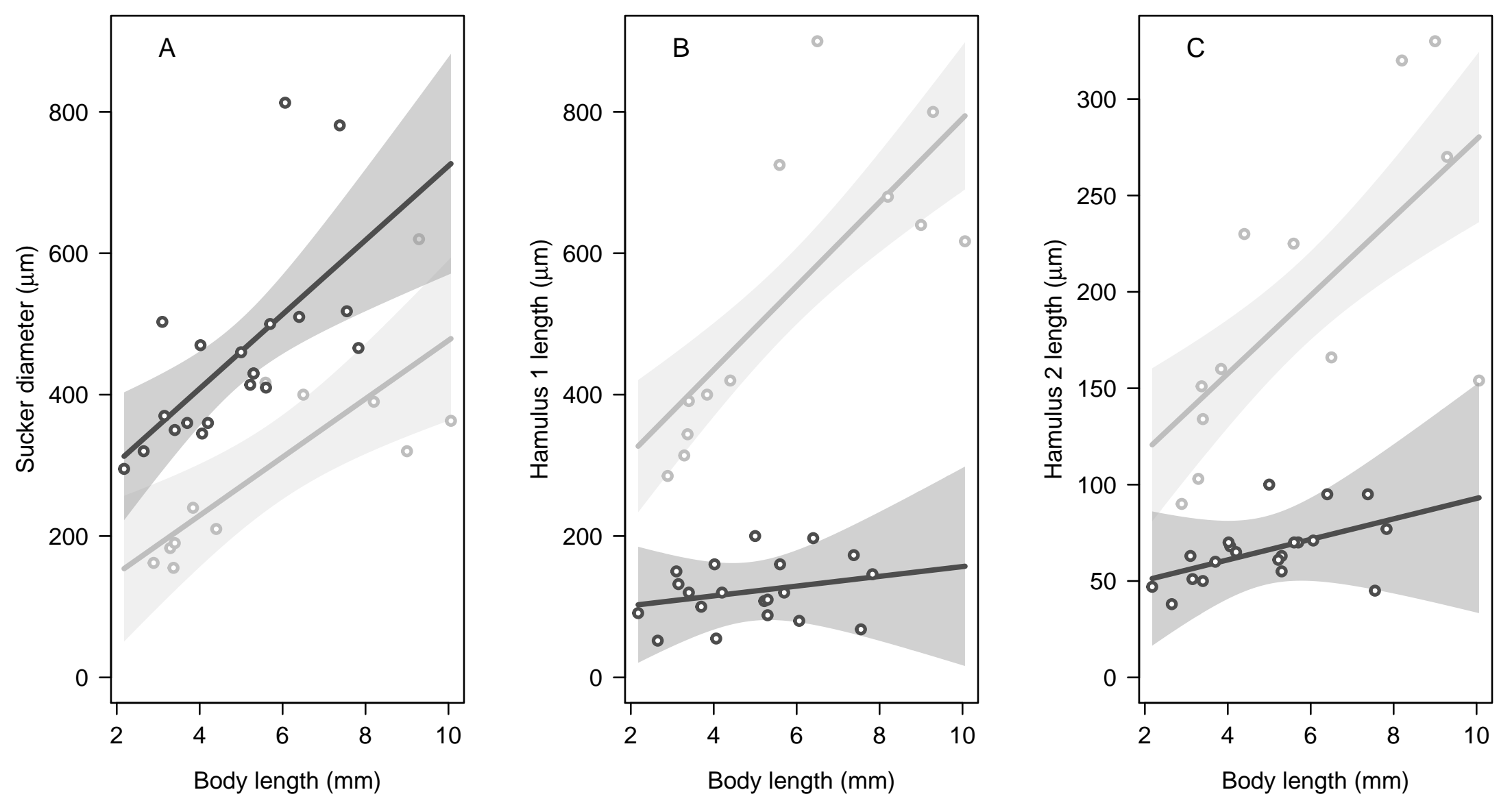
site:

urinary bladder

host:

parasite:

U. malayi

Cyclemys amboinensis
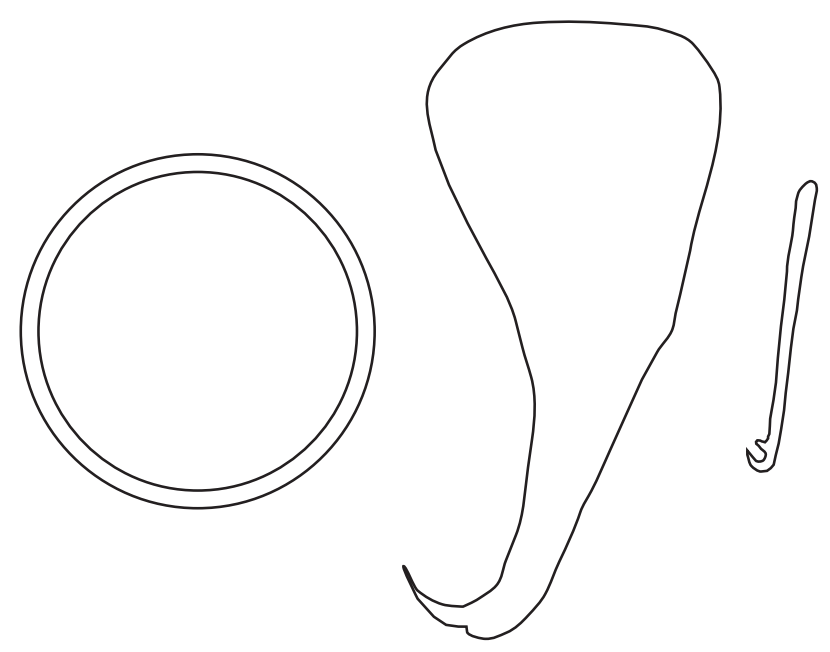

host:

Siebenrockiella crassicollis oral cavity/pharynx

$P$. asiaticus

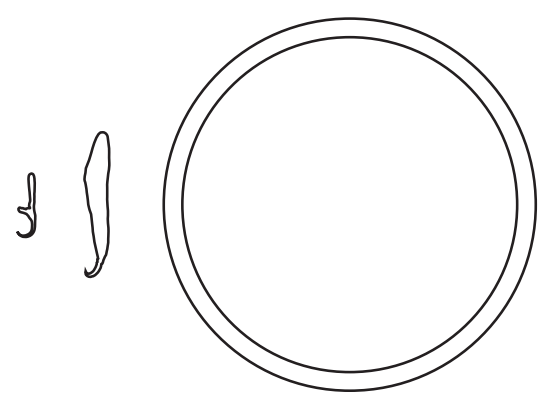

parasite: U. siebenrockiellae

P. renschi
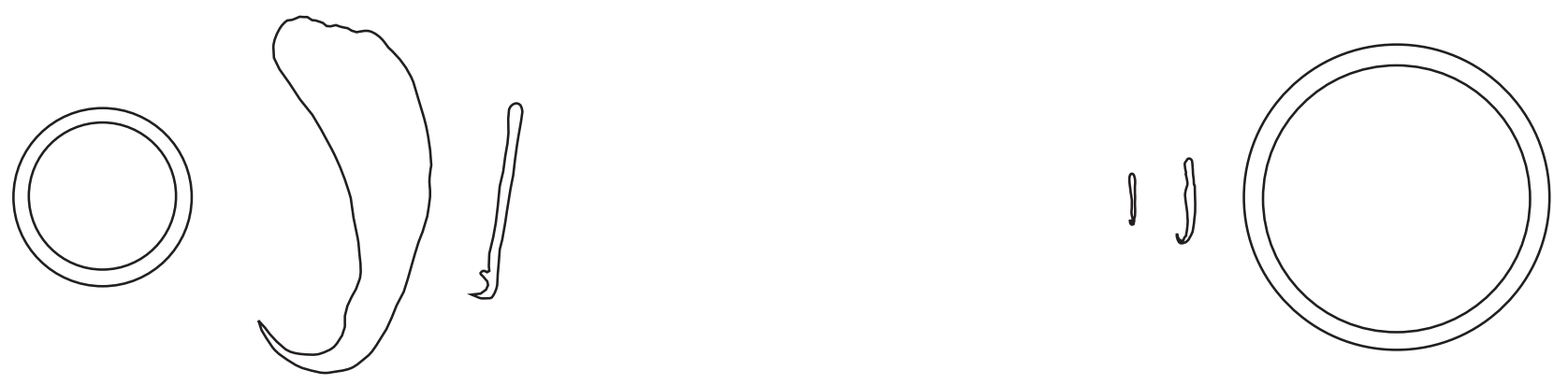

host:

Ocadia sinensis

parasite: U. ocadiae

P. microrchis
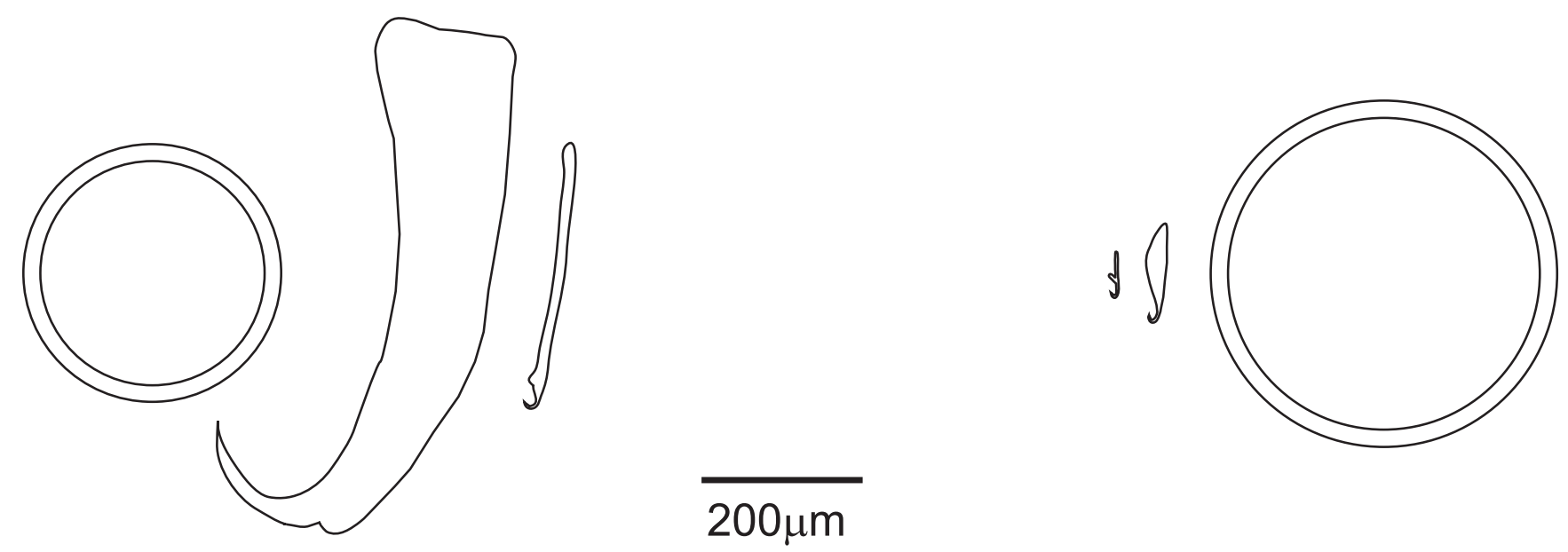


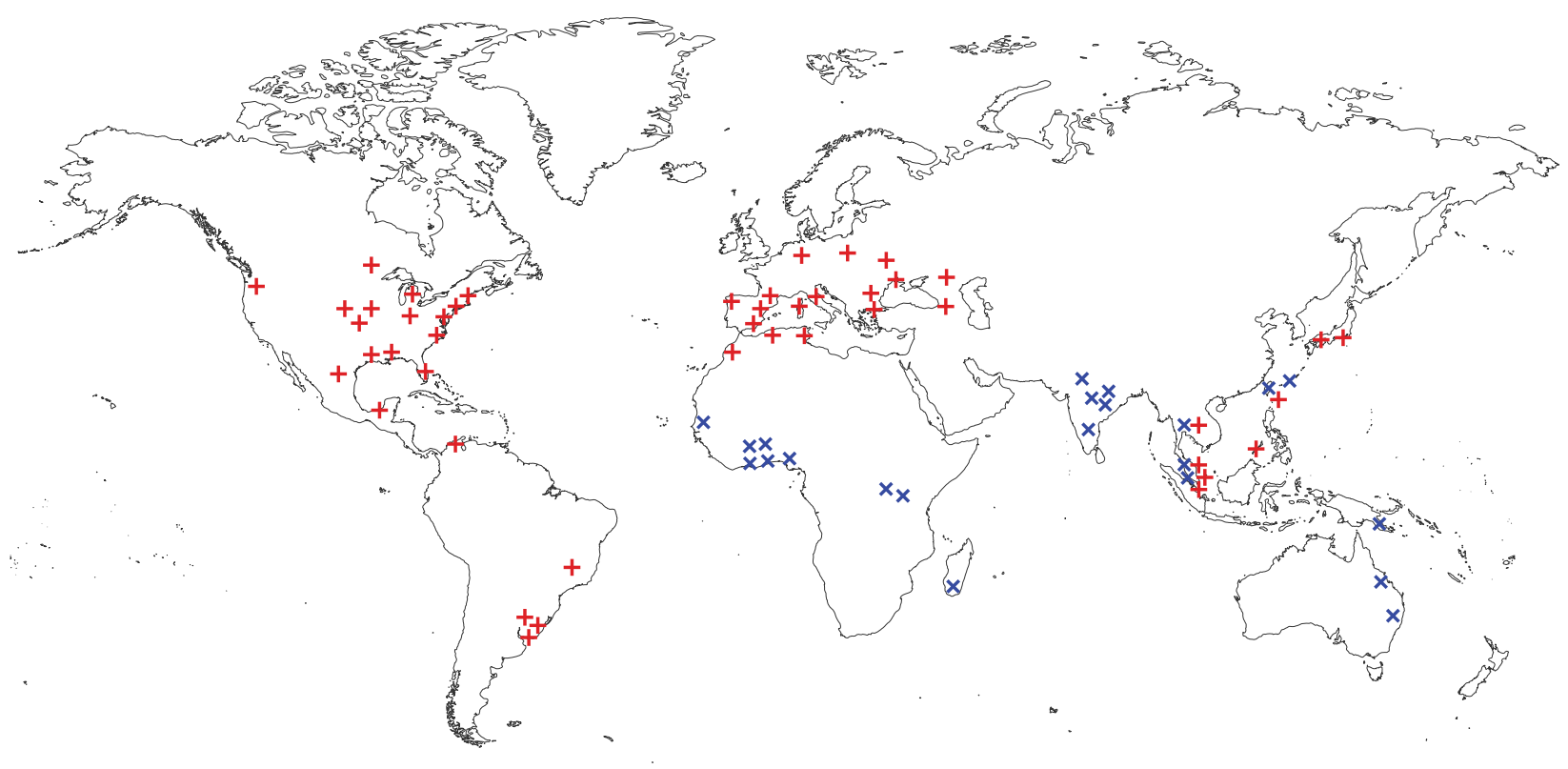

